10 - ORIGINAL ARTICLE

CLINICAL INVESTIGATION

\title{
Virtual planning and construction of prototyped surgical guide in implant surgery with maxillary sinus bone graft $^{1}$
}

\author{
Renato Jahjah Cunha Martins', Henrique Manoel Lederman² \\ ${ }^{1} \mathrm{PhD}$, Image Diagnosis Department, Federal University of Sao Paulo (UNIFESP), Brazil. Conception and design of the study, acquisition of data, \\ manuscript writing, critical revision. \\ ${ }^{2}$ Full Professor, Image Diagnosis Department, UNIFESP, Sao Paulo-SP, Brazil. Manuscript writing, final approval of the version to be published.
}

\begin{abstract}
PURPOSE: To evaluate the efficacy of associating techniques of bone grafting in the maxillary sinus with the use of a prototyped surgical guide for planning and positioning dental implants in total edentulous maxillae, rehabilitated after six months.

METHODS: Eight patients consecutives with totally edentulous maxilla presenting few remaining bone in the posterior alveolar ridge, associated with pneumatization of the maxillary sinus were selected. Twenty eight Brånemark RP 10mm implants were installed in 14 maxillary sinuses. The surgical planning for the implant installation was performed with the DentalSlice software by means of a computerized tomography. The obtained images were used for building a surgical guide that, placed over the maxilla, showed the exact position for the implants installation (prototyped surgical guide). The portion of the implants that went into the maxillary sinus was covered by an autogenous bone graft.
\end{abstract}

RESULTS: The patients were re-evaluated six months after the surgery and a $100 \%$ success rate was achieved. All of the implants presented no mobility or symptoms, permitting an oral rehabilitation with total fixed screw-retained prosthesis over the implants.

CONCLUSION: The technique of associating implants and bone graft in the maxillary sinus aided by a prototyped guide planned on DentalSlice has showed itself efficient for positioning implants and for quantifying and locating the bone graft.

Key words: Dental Implantation. Sinus Floor Augmentation. Bone Transplantation. Surgery, Computer-Assisted. Maxilla. 


\section{Introduction}

Osseointegrated implants represent a treatment alternative that, in many situations, can be considered as the first choice for rehabilitation when one or more natural dental elements are missing. The introduction of the concept of osseointegration made it possible to offer an additional prosthetic resource for retention and stability to edentulous individuals, providing satisfactory functional, aesthetical and psychological results ${ }^{1}$.

The osseointegrated implantology developed by Brånemark ${ }^{2}$ is based on a protocol comprising two surgical steps defining that, after the implant installation, the surgical sites must not receive load for a period of three to six months so that the bone can heal and, thus, to ensure the osseointegration between implant and bone. Nevertheless, when the oral rehabilitation is performed according to the conventional surgical protocol it frequently harms the individual's professional, social and affective life due to the wait for the final rehabilitation.

Oral rehabilitation by means of osseointegrated implants demands a sufficient quantity of bone, permitting a good anchorage. The healing of the resorbed alveolar bone is one of the current challenges for clinical dentistry, considering that a proper height and width are necessary to accommodate an implant with adequate dimensions and with an axial angulation that makes it possible to fabricate the prosthesis. In patients with inadequate quantity of posterior maxillary bone there is the possibility of performing a maxillary sinus lift with proved efficacy and predictability, if performed with the aid of bone substitutes to restore a sufficient quantity of alveolar bone ${ }^{3}$.

Image examinations by means of computerized tomography made it possible to develop specific software for studying the skeletal facial anatomy in detail and permitting an excellent image-based demonstration of the medullary and cortical bone, of their irregular borders and the relation of the dental roots to the adjacent structures. These software are used for tridimensional surgical planning, permitting the insertion of the implants with high precision. With this technique it is possible to immediately install a provisional implant-supported restoration on the maxillary and/or mandibular region, making it possible to perform the surgery with minimal incisions, providing a much lesser traumatic surgery for the patient and, consequently, a more comfortable post-surgery recovery, with less pain and less edema $^{4-9}$.

The purpose of this study was to evaluate the efficacy of associating techniques of bone grafting in the maxillary sinus with the use of a prototyped surgical guide for planning and positioning dental implants in totally edentulous maxillae, rehabilitated after six months.

\section{Methods}

The study was approved by the Research Ethics Committee, Federal University of Sao Paulo. The patients agreed to participate of the study according to Free and Clarified Consent Term.

For this study, eight patients with totally edentulous maxillae were selected, regardless of gender or age, presenting proper clinical and systemic conditions for being submitted to the surgical procedure, during the period from January 2010 to March 2012, coming from a Private Practice. The main complaint reported by the patients was the discomfort of using conventional total dentures.

The patients were submitted to helical tomography and the results of the scans were transferred to the DentalSlice software, which permits to simulate and plan the best place for the implant installation (Figure 1). The criterion of inclusion for the patients in the study was that the quantity of bone available between the crest of the posterior maxillary ridge and the inferior part of the maxillary sinus ranged from 4 to $8 \mathrm{~mm}$.

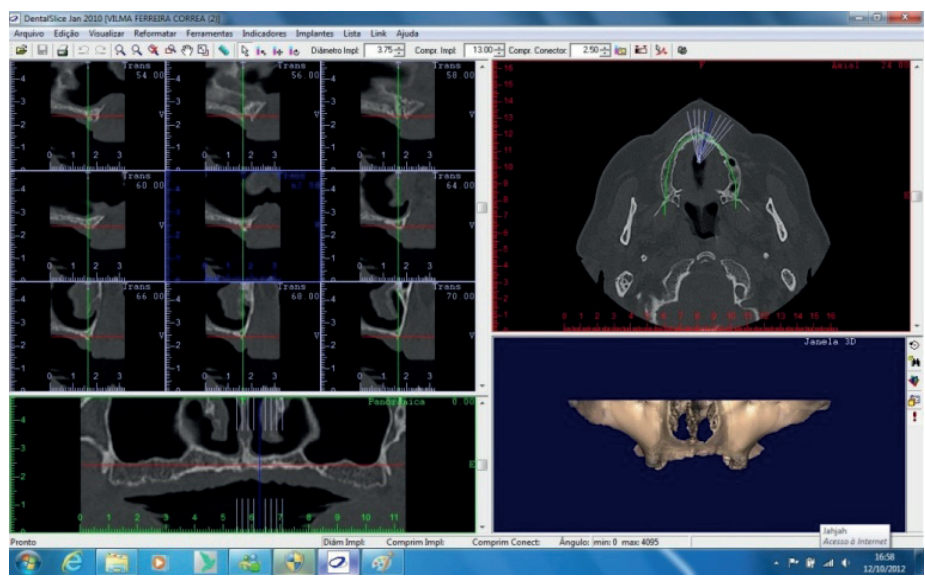

FIGURE 1 - Images of the helical computerized tomography, presenting the sagittal, coronal and axial slices, inserted in DentalSlice.

Two $3.75 \mathrm{~mm}$ x $10 \mathrm{~mm}$ Brånemark System ${ }^{\circledR}$ (Nobel Biocare $^{\circledR}$ ) implants were planned for each maxillary sinus. On the anterior areas of the total sample and on the left posterior part of two patients that had sufficient bone, two more implants were installed but were not evaluated on this study.

To select the installation places for the implants the planning was based on the type of prosthesis indicated for the patients, the number of implants and the distribution of the 
masticatory forces. On the DentalSlice software, the implants were inserted according to the defined prosthetic rehabilitation, considering their length and the diameter as well as the shape of the alveolar arch. With the aid of the DentalSlice software the necessary amount of bone was calculated for the maxillary sinus augmentation, exceeding the height of the implants by $3 \mathrm{~mm}$ (Figure 2).

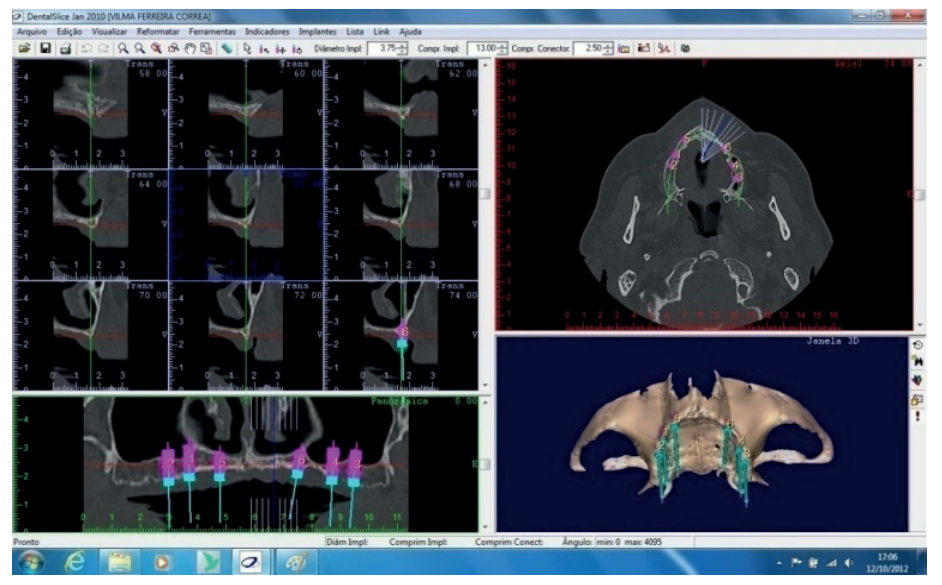

FIGURE 2 - Planning of the positioning of the implants for oral rehabilitation with total fixed prosthesis.

We proceeded, then, to sending the planning of the positioning for the implant installation to Bioparts, the company that fabricated a prototyped surgical guide and a biomodel of the maxilla, allowing, thus, a better pre-visualization and planning of the surgery.

The patient was submitted to the surgical procedure under local infiltrative anesthesia of the maxillary nerves with 1:200.000 articaine. Guided by the prototype, an incision was performed on the crest of the alveolar ridge with mucoperiosteal reflection until the complete exposure of the lateral part of the maxillary bone, close to the maxillary sinuses (Figure 3).

With the surgical guide in position, by means of the perforations for inserting the implants, a pre-demarcation was performed on the bone with round burs in order to facilitate the installation of the implants (Figure 4). Next, the bone was cut defining a rectangular shape and the opening of the lateral wall of the maxillary sinus was performed with curettes and, with very delicate maneuvering, the sinus membrane was displaced from its inferior portion (Figure 5).

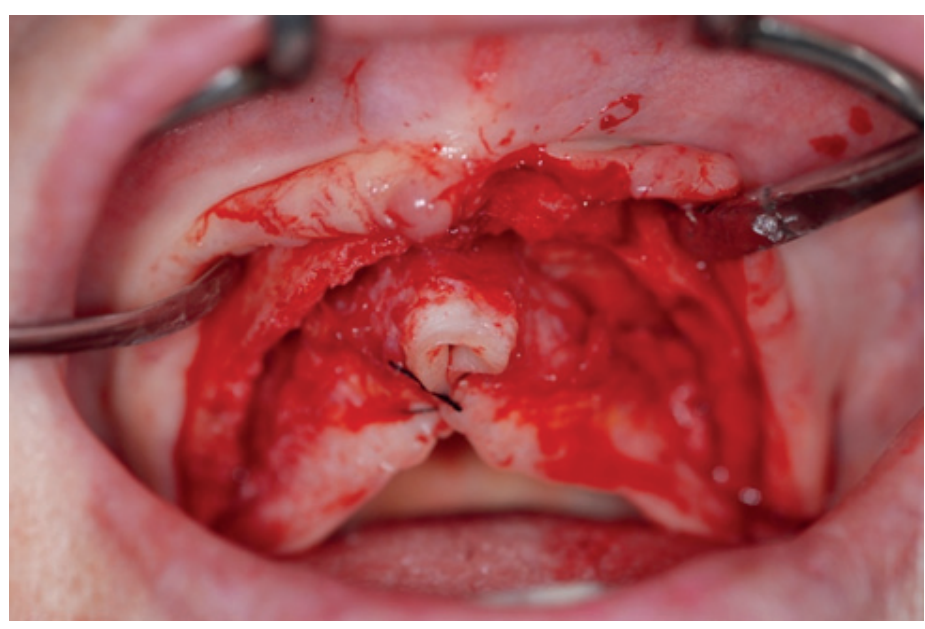

FIGURE 3 - Incision over the alveolar ridge, divulsion and exposure of the maxillary bone.

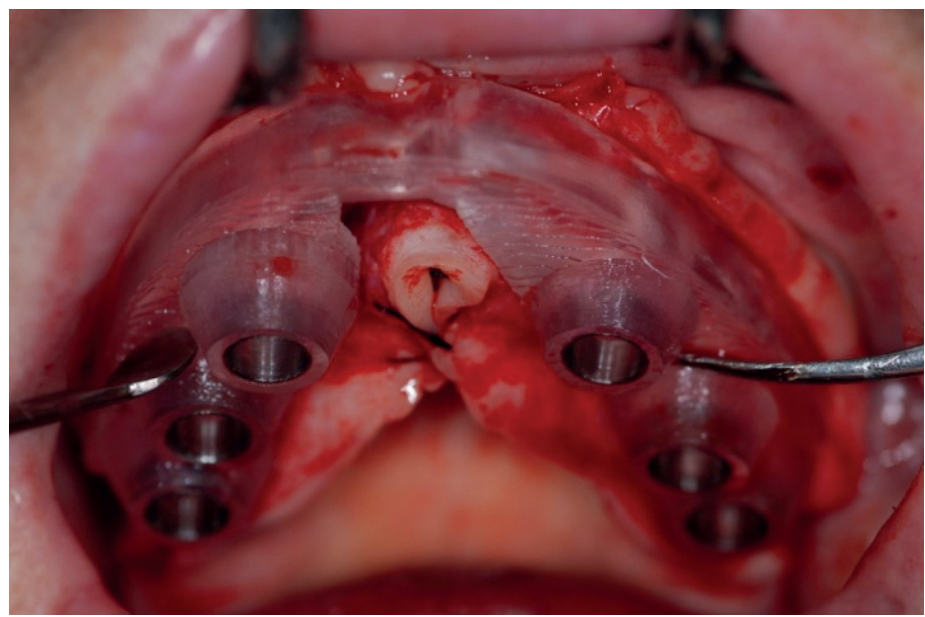

FIGURE 4 - Positioning of the surgical guide to orientate the location of the implants and the access to the maxillary sinuses.

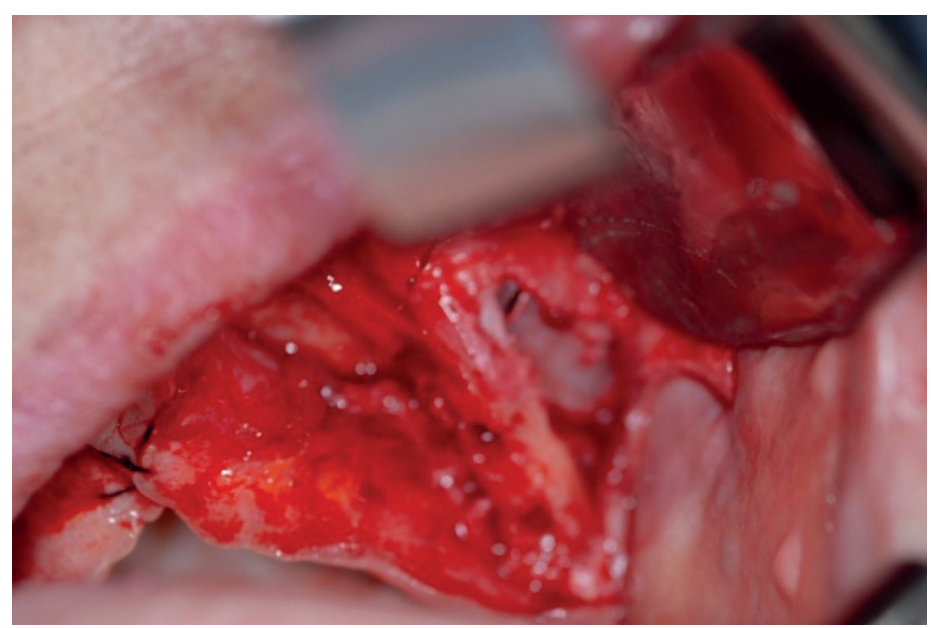

FIGURE 5 - Opening of the maxillary sinus with displacement of the sinus membrane for the insertion of the implants and the autogenous graft.

The surgical guide is repositioned in the mouth and the perforation of the alveolar ridge begins using a $2 \mathrm{~mm}$ bur until the 
bone is completely ruptured, invading the maxillary sinus. For the implant installation we followed the sequence of burs used in the conventional protocol protecting the sinus membrane avoiding, thus, any possible damage (Figure 6).

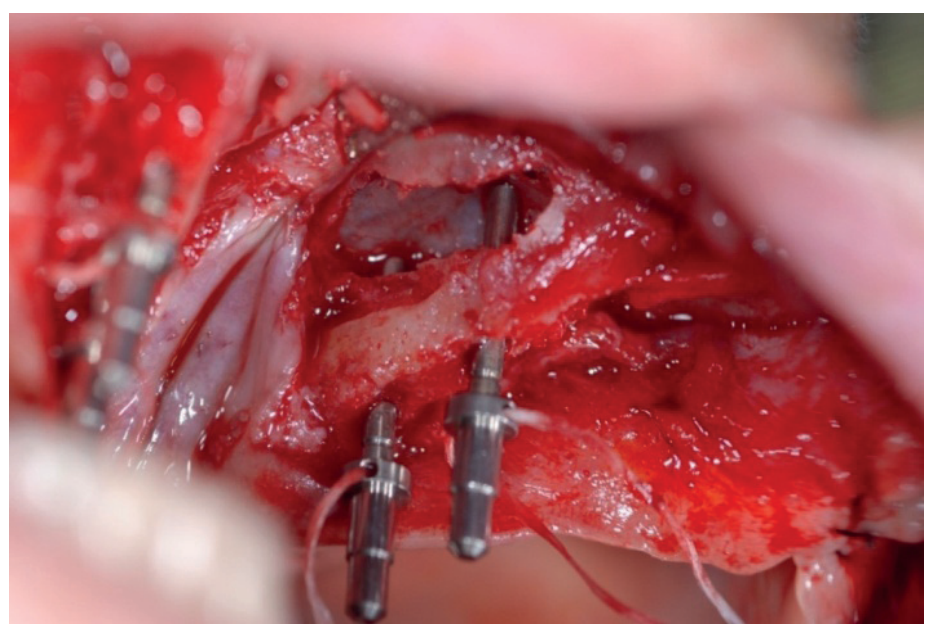

FIGURE 6 - Bone perforation performed according to the conventional sequence of burs for implant installation, ending the procedure with the invasion of the maxillary sinus.

On the next step, the receptor site of the graft was coated with gauzes damped in physiologic solution, waiting for the preparation of the autogenous graft. The inferior alveolar and buccal nerves were anesthetized with 1:200.000 articaine and a retromolar incision was made following the oblique line of the mandible, using trephine burs to collect bone for the graft.

The bone was mashed and put into a disposable syringe to check the volume to be used on the receptor site. The implants were coated with particulate bone and the flap was repositioned and sutured with 5-0 mononylon. The sutures were removed seven days after the surgery (Figure 7).

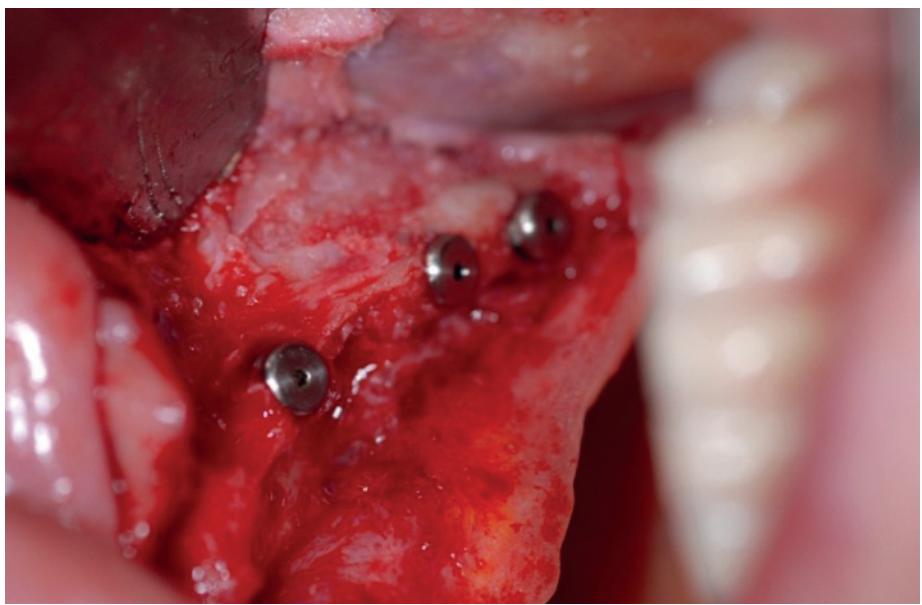

FIGURE 7 - Finalized implants installed on the alveolar ridge and covered by the autogenous graft.
After the surgical procedure, the patients used conventional total dentures with a relief of the support over the operated alveolar ridge. The patients were oriented not to chew consistent food, which could damage the region of the implants, and they also should not sleep wearing their dentures.

A surgery was performed six months later to uncover the implants, using the same surgical guide from the first stage to help locating those. On this step the intermediate abutments that will connect the implants to the prosthesis were installed and protected by healing covers, which have the objective of preventing an invagination of the gingival tissue over the abutments. Additionally, some adjustments were performed on the provisional dentures to match the new clinical condition.

After seven days a panoramic radiography was made to evaluate the situation of the implants and the efficacy of the bone graft. Next, impressions of the mouth were taken with the implants in position, followed by the elaboration and fabrication of the new prosthesis, with the proper aesthetical and functional tests. The patients were advised about the care with hygiene and the annual follow-up appointments (Figure 8).

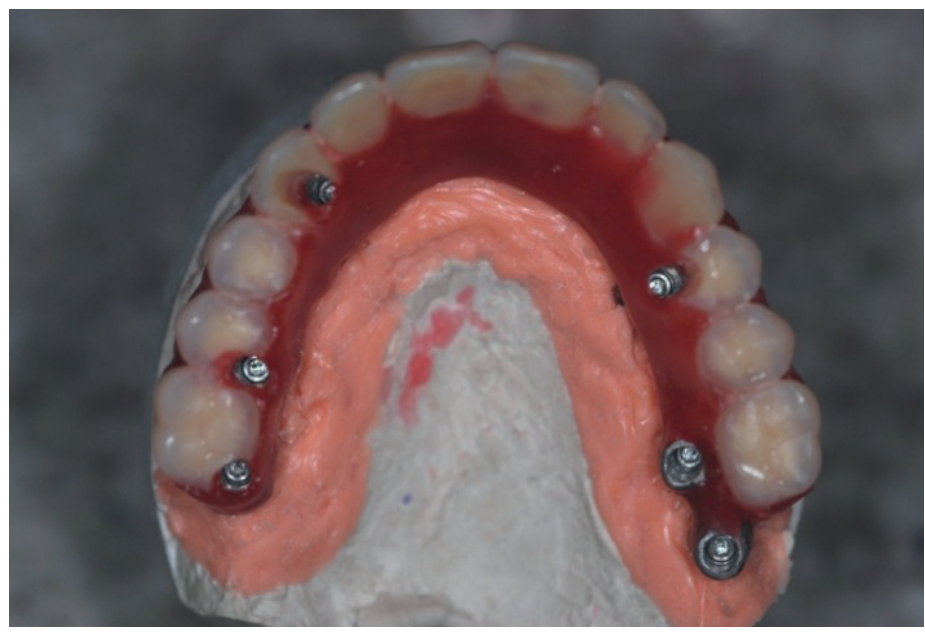

FIGURE 8 - Fabrication of the prosthesis in a cast following the orientations of occlusion and antagonist teeth.

\section{Results}

The sample consisted of eight patients with completely edentulous maxillae (two males and six females) aging from 49 to 70 years old, not considering age or sexual dimorphism. Patients presented a posterior alveolar ridge with heights between 4.5 and $8.0 \mathrm{~mm}$ measured between the lowest part of the maxillary sinus and the bony crest of the alveolar ridge, and a minimal thickness of $5 \mathrm{~mm}$ determined by the distance between the most lateral and the most medial parts of the alveolar bone (Figure 9). In six patients the implants were installed bilaterally and in two they 
were installed on the left posterior area, and in this case the right maxillary sinuses were considered.

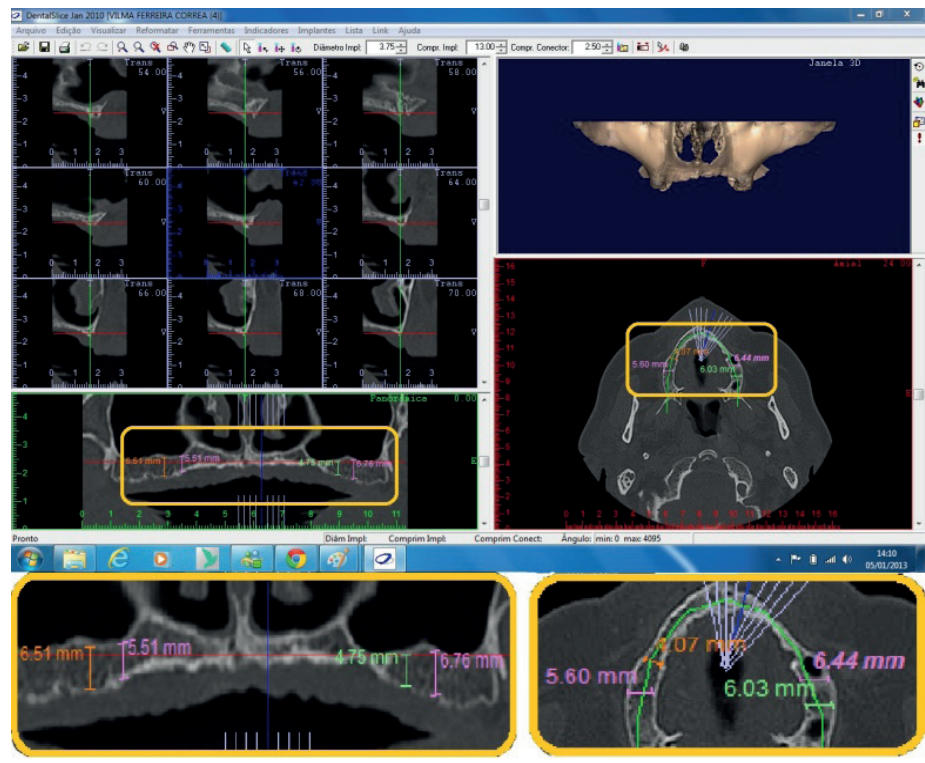

FIGURE 9 - Bone measurements of the alveolar ridge in height and buccal-palatine width on the anterior region and the region of the maxillary sinuses.

One week after the second surgical stage, with the aid of a conventional panoramic radiograph, it was possible to verify if the installed implants were on the planned places and integrated to the maxilla. No image of bone discontinuity was observed between the graft and the maxillary bone, and the implants had a close contact with both the original maxilla and the grafted bone (Figure 10). The implants were clinically tested for mobility, absence of pain, infections and neuropathies. It was possible to verify that all the implants had no mobility and no symptoms (Figure 11).

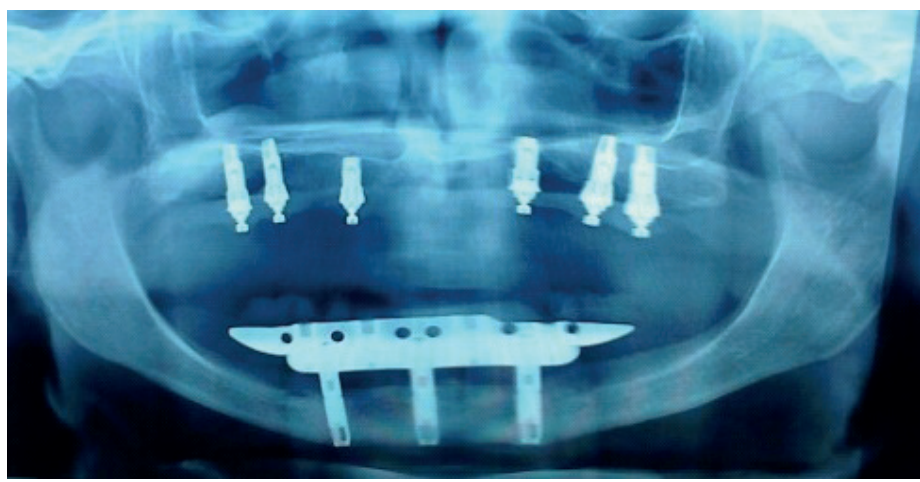

FIGURE 10 - Conventional panoramic radiography showing the implants and the autogenous bone graft integrated to the stomatognathic system.

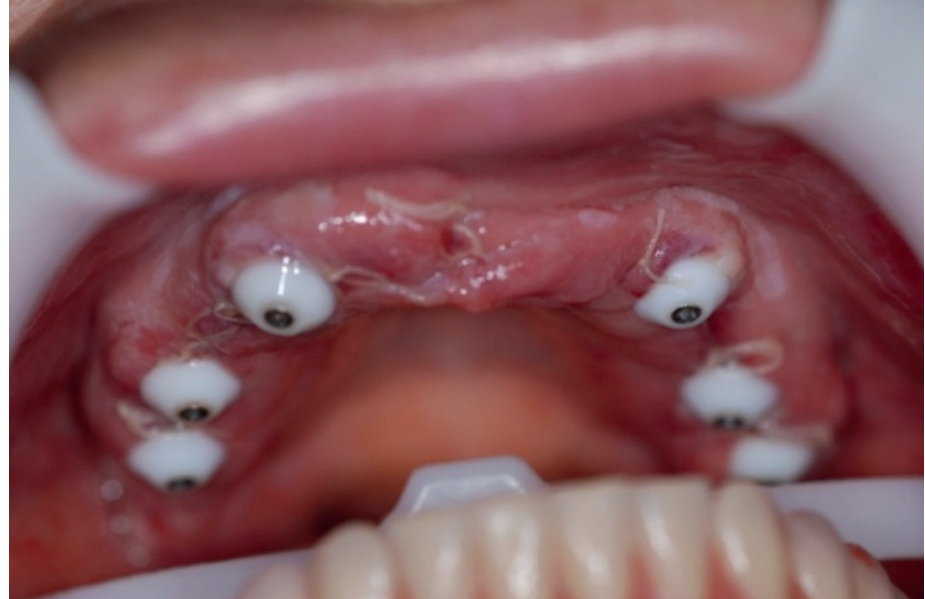

FIGURE 11 - Post-surgery aspect of the reopening surgery when tests of mobility and sensitivity are performed.

It was observed on the final panoramic radiography that the implants and the prosthesis were positioned according to the planning from the DentalSlice software, and it was possible to perform the oral rehabilitation of all the patients with the proposed surgical technique. The patients expressed their satisfaction with the stability of the dentures and with the final aesthetical outcome of the treatment (Figures 12 and 13).

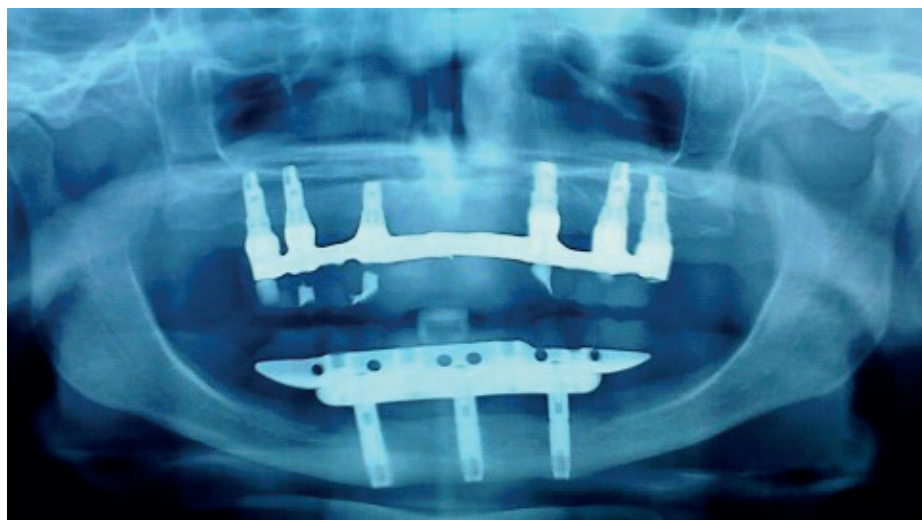

FIGURE 12 - Final panoramic radiography of the prosthesis installed over the implants.

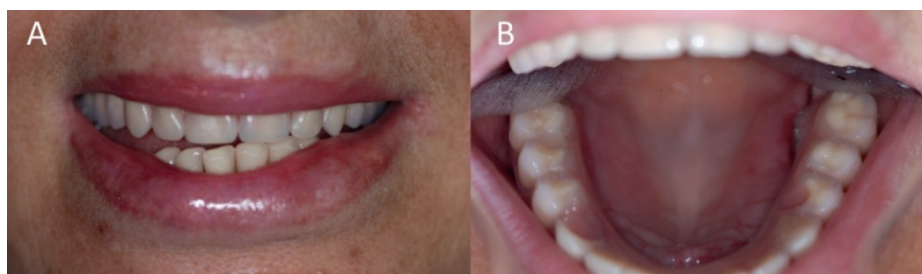

FIGURE 13 - Finishing of the oral rehabilitation with the implantsupported prosthesis. A. Frontal. B. Occlusal. 


\section{Discussion}

The main complaints of the patients about total dentures are instability, displacement, discomfort and the embarrassment when they need to remove them. When the denture is the upper one, there are references of loss of gustation due to the palatine portion impeding the tongue from touching the mucosa, blocked by the acrylic resin of the denture.

For this reason some adhesive materials were developed to aid on the retention of the prosthesis. Nevertheless, patients that need a total denture and use this resource almost always express other complaints, such as the taste, which can be unpleasant, and that these adhesives frequently have a sudden loss of effect during their use making the dentures unstable. But in no case at all, with this resource of retention, they would suppress the bother of the lack of gustation due to the resin on the palate.

When implants are inserted in the planning of a prosthetic rehabilitation of edentulous patients, the use of computerized tomography becomes an important instrument, because it is possible to have a broad visualization of the dental arches and of all their anatomic structures, both the alveolar bone and the adjacent structures.

According to the biomechanical concepts, on CTs it is possible to program the quantity and the disposition of the implants aiming for a total rehabilitation of the edentulous area, height and width of the alveolar bone, anatomical structures close to the alveolar ridge and the distribution of the masticatory forces on the prosthesis. On the posterior regions of the maxilla the reduction of alveolar bone is common, with pneumatization of the maxillary sinuses in a significant number of edentulous patients.

The present study was based on the techniques of maxillary sinus floor lift described by Boyne ${ }^{10}$ and Brånemark ${ }^{11}$ who demonstrated a bone formation in the sinus cavity permitting the installation of implants in the posterior maxilla, contradicting Jacomini $^{12}$, who referred that it would not be possible to rehabilitate the resorbed posterior maxilla with dental implants.

One of the inconveniences of the technique of maxillary sinus lift is that the treatment with implants requires a second surgical intervention. On studies of grafts in the maxillary sinus, the bone used was exclusively autogenous bone gathered from different donor regions, such as: iliac crest, part of a rib, tibia or the external portion of the cranial bone ${ }^{13-15}$.

However, these areas require a more invasive procedure increasing, thus, the surgical risk and even the cost of the oral rehabilitation treatment. With the objective of attenuating the problems, the oral cavity becomes the area of selection for the collection of the graft, although, anatomically, it is limited in bone quantity as a donor region, restraining the clinical indications.

On the literature are referred the biomaterials used as bone substitutes in surgeries of maxillary sinus floor lift ${ }^{16-22}$. The mentioned studies investigated the efficiency of bone grafts associated or not to other biomaterials for maxillary sinus lift. The whole of these works showed the efficiency of the technique regardless of the material used. With the objective of homogenizing the sample, in this study only autogenous "gold standard" graft was used, since it is osteogenic, osteoinductive and osteoconductive ${ }^{13}$.

Surgeries on the donor site for removing the autogenous graft in the maxillary sinus can be intra or extraoral. One of the advantages of the intraoral region is that the procedure can be performed in the dental office under local anesthesia, broadening the indications and facilitating its execution with reduced financial costs, though the bone amount, in some cases, is insufficient.

On the other hand, in the extra-oral region it becomes possible to obtain a larger and sufficient amount of bone. However, this situation involves, besides two surgical settings, one for the bone collection and the other for the graft and implants placement, a hospital intervention, many times under general anesthesia, increasing the surgical risk and the costs with hospitalization ${ }^{23}$

In this study the intraoral donor areas selected for gathering the autogenous graft were the retromolar region and the mandibular symphisis, according to the studies of Caubet et al. ${ }^{18}$, Wheeler et al..$^{23}$ and Johansson et al. ${ }^{24}$ whom also used the oral cavity as a donor site. The implants were installed at the same surgical step of the bone graft procedure, with a minimal limit of $4 \mathrm{~mm}$ of alveolar bone height ${ }^{10,11,20,24}$.

The reference for implant selection was the study performed by ${ }^{25}$, demonstrating that a $3.75 \mathrm{~mm} \times 10 \mathrm{~mm}$ implant is sufficient for supporting a dental element for oral rehabilitation. This way the maxillary sinuses would be minimally invaded requiring a smaller quantity of bone graft to completely cover the implants.

With the measurements obtained on the computerized tomography exam and the planning of the implants positioning it was possible to calculate de volume of graft, customizing the necessary amount of bone for each maxillary sinus of each studied patient. After the surgery of maxillary sinus augmentation, contrasting with the study of Urban and Lozada ${ }^{21}$, no collagen barrier was used, because during the sutures of the surgical flap the periosteum itself was used for closing the access opening to the maxilla.

The correct positioning of the implants allows easier prosthetic procedures and also directs the biomechanical forces to 
Virtual planning and construction of prototyped surgical guide in implant surgery with maxillary sinus bone graft

the axis. For this to happen a rigorous planning of the bone sites and the angles of implantations must be made, and it is necessary to use a transference device, such as acrylic surgical guide, necessarily stable and rigid ${ }^{26}$.

To establish the relation between pre-surgical planning and the surgery itself some software were developed and are available on the market for virtual planning and implant installation ${ }^{27,28}$. There is a lack of articles in the literature addressing the efficacy of the transference of images from the study of implant placement to the surgical field ${ }^{29}$. Di Giacomo et al. ${ }^{30}$ used six surgical guides in four patients with 21 implants inserted and observed differences in the distances between the planned and actual implant positions at the implant level of, in average, $1.45 \mathrm{~mm}$ and $2.99 \mathrm{~mm}$, respectively. Comparing the results above with those obtained by Chen et al. ${ }^{31}$ it is possible to state that the precision of positioning of the surgical guide increases when it is supported simultaneously by bone and the remaining tissues.

Based on the studies of Di Giacomo et al..$^{30}$ and Sament et $a l .^{32}$, the DentalSlice software was selected by its easy access and efficacy for planning. The software permits the insertion of images of the implants simulating clinical situations in 3D overlapping the anatomical structures as well as the diameter, length and positioning of the implants, which can be visualized individually ${ }^{26}$.

Based on the concepts of osseointegration, the information regarding the bone measurements of the alveolar ridge in height and buccal-palatine width, the dimensions of the maxillary sinuses and the positioning of the implants, with the DentalSlice software the portion of the implant that invades the maxillary sinus can be precisely defined. On the computer screen, with these information and with the aid of a tool from the software itself to verify dimensions it was possible to quantify the bone volume necessary for the maxillary sinus graft surgery. It is unanimous in the literature that the prototyped guide facilitates the transference of the planning performed on the computer to the surgical site. With the technique of fabricating the surgical guide it was possible to personalize the performed planning, transforming complex clinical situations in simplified surgeries ${ }^{26,27}$.

The precision of the virtual planning and the results obtained in the surgery were broadly checked, certifying the technical reliability ${ }^{5-8}$. Supported by these concepts we associated in this study the computerized tomography, the virtual planning of the implant installation surgery by means of the DentalSlice software, the confection of a prototyped surgical guide and the graft in the maxillary sinus, aiming to reduce time and optimize the oral rehabilitation treatment.

\section{Conclusion}

The technique of associating implants and bone graft in the maxillary sinus aided by a prototyped guide planned on DentalSlice has showed itself efficient for positioning implants and for quantifying and locating the bone graft.

\section{References}

1. Capelli M, Zuffetti F, Del Fabbro M, Testori T. Immediate rehabilitation of the completely edentulous jaw with fixed prostheses supported by either upright or tilted implants: a multicenter clinical study. Int J Oral Maxillofac Implants. 2007;22(4):639-44.

2. Brånemark PI. Intra-osseous anchorage of dental prosthesis: experimental studies. Scand J Plast Reconstr Surg. 1969;3(2):81100.

3. Dalapicula SS, Vidigal Junior GM, Conz MB, Cardoso ES. Características físico-químicas dos biomateriais utilizados em enxertias ósseas: uma revisão crítica. ImplantNews. 2006;3(5):48791.

4. Maiorana C, Sigurta D, Mirandola A, Garlini G, Santoro F. Sinus elevation with alloplasts or xenogenic materials and implants: an up to 4 year clinical and radiologic follow-up. Int J Oral Maxillofac Implants. 2006;21(3):426-32.

5. Van Assche N, van Steenberghe D, Quirynen M, Jacobs R. Accuracy assessment of computer-assisted flapless implant placement in partial edentulism. J Clin Periodontol. 2010;37(4):398-403.

6. Viegas VN, Dutra V, Pagnoncelli RM, de Oliveira MG. Transference of virtual planning and planning over biomedical prototypes for dental implant placement using guided surgery. Clin Oral Implants Res. 2010;21(3):290-5.

7. Nokar S, Moslehifard E, Bahman T, Bayanzadeh M, Nasirpouri F, Nokar A. Accuracy of implant placement using a CAD/CAM surgical guide: an in vitro study. Int J Oral Maxillofac Implants. 2011;26(3):520-6.

8. D'haese J, Van De Velde T, Komiyama A, Hultin M, De Bruyn $\mathrm{H}$. Accuracy and complications using computer-designed stereolithographic surgical guides for oral rehabilitation by means of dental implants: a review of the literature. Clin Implant Dent Relat Res. 2012;14(3):321-35.

9. Soares MM, Harari ND, Cardoso ES, Manso MC, Conz MB, Vidigal $\mathrm{Jr}$ GM. An in vitro model to evaluate the accuracy of guided surgery systems. Int J Oral Maxillofac Implants. 2012;27(4):824-31.

10. Boyne JP, James RA. Grafting of the maxillary sinus flour autogenous marrow and bone. J Oral Surg. 1980;38(8):613-6.

11. Brånemark PI, Adell R, Albrektsson T, Lekholm J, Rockler B. An experimental and clinical study of osseointegrated implants penetrating the nasal cavity and maxillary sinus. J Oral Maxilofac Surg. 1984;42(8):497-505.

12. Jacomini A. Eficácia do procedimento de levantamento do seio maxilar em suportar um implante osseointegrado em função. BCI. 1998;5(1):57-62.

13. McAllister BS, Haghighat K. Bone augmentation techniques. J Periodontol. 2007;78(3):377-96.

14. Zizelmann C, Schoen R, Metzger MC, Schmelzeisen R, Schramm A, Dott B, Bormann KH, Gellrich NC. Bone formation after sinus augmentation with engineered bone. Clin Oral Implants Res. 
2007;18(1):69-73.

15. Sakka S, Krenkel C. Simultaneous maxillary sinus lifting and implant placement with autogenous parietal bone graft: outcome of 17 cases. J Craniomaxillofac Surg. 2011;39(3):187-91.

16. Kühl S, Götz H, Hansen T, Kreisler M, Behneke A, Heil U, Duschner $\mathrm{H}$, d'Hoedt B. Three-dimensional analysis of bone formation after maxillary sinus augmentation by means of microcomputed tomography: a pilot study. Int $\mathrm{J}$ Oral Maxillofac Implants. 2010;25(5):930-8.

17. Borges FL, Dias RO, Piattelli A, Onuma T, Cardoso LAG, Salomão M, Scarano A, Ayub E, Shibli JA. Simultaneous sinus membrane elevation and dental implant placement without bone graft: a 6-month follow-up study. J Periodontol. 2011;82(3):403-12.

18. Caubet J, Petzold C, Sáez-Torres C, Morey M, Iriarte JI, Sánchez J. Sinus graft with safe scraper: 5-year results. J Oral Maxillofac Surg. 2011;69(2):482-90.

19. Fuerst G, Strbac GD, Vasak C, Tangl S, Leber J, Gahleitner A, Gruber R, Watzek G. Are culture-expanded autogenous bone cells a clinically reliable option for sinus grafting? Clin Oral Implants Res. 2009;20(2):135-9.

20. Manso MC, Wassal T. A 10-year longitudinal study of 160implants simultaneously installed in severely atrophic posterior maxillas grafted with autogenous bone and a synthetic bioactive resorbable graft. Implant Dent. 2010;19(4):351-60.

21. Urban IA, Lozada JL. A prospective study of implants placed inaugmented sinuses with minimal and moderate residual crestal bone: results after 1 to 5 years. Int J Oral Maxillofac Implants. 2010;25(6):1203-12.

22. Pjetursson BE, Ignjatovic D, Matuliene G, Brägger U, Schmidlin K, Lang NP. Transalveolar maxillary sinus floor elevation using osteotomes with or without grafting material. Part II: radiographic tissue remodeling. Clin Oral Implants Res. 2009;20(7):677-83.

23. Wheeler SL, Holmes RE, Calhoun CJ. Six-year clinical and histologic study of sinus-lift grafts. Int J Oral Maxillofac Implants. 1996;11(1):26-34.

24. Johansson LA, Isaksson S, Lindh C, Becktor JP, Sennerby L. Maxillary sinus floor augmentation and simultaneous implant placement using locally harvested autogenous bone chips and bone debris: a prospective clinical study. J Oral Maxillofac Surg. 2010;68(4):837-44.

25. Brånemark PI. Intra-osseous anchorage of dental prosthesis: experimental studies. Scand J Plast Reconstr Surg. 1969;3(2):81100.

26. Chilvarquer I, Chilvarquer LW, Hayek J. A estereolitografia na Implantodontia avançada: conceitos, indicações e usos. ImplantNews. 2004;1(1):69-72.

27. Viana Neto A, Neves PJC, Madruga FATTA, Rocha RS, Carvalho RWF. Cirurgia guiada virtual para reabilitação oral: revisão de literatura e relato de caso. Rev Cir Traumatol Bucomaxilofac. 2009;9(2):45-52.

28. Barros CAVS, Vieira DM, Reis ES, Rossetti PHO, Padovan LEM, Francischone CE. Estabelecimento de um protocolo clínico controlado para a cirurgia guiada sem retalho em maxilas totalmente edêntulas. ImplantNews. 2010;7(3):371-8.

29. Al-Harbi SA, Sun AYT. Implant placement accuracy when using stereolithographic template as a surgical guide: preliminary results. Implant Dent. 2009;18(1):46-56.

30. Di Giacomo GAP, Cury PR, Araujo NS, Sendyk WR, Sendyk CL. Clinical application of stereolithographic surgical guides for implant placement: preliminary results. J Periodontol. 2005;76(4):503-7.

31. Chen X, Yuan J, Wang C, Huang Y, Kang L. Modular preoperative planning software for computer-aided oral implantology and the application of a novel stereolithographic template: a pilot study. Clin Implant Dent Relat Res. 2010;12(3):181-93.

32. Sarment DP, Sukovic P, Clinthorne N. Accuracy of implant placement with stereolithographic surgical guide. Int $\mathrm{J}$ Oral Maxillofac Implants. 2003;18(4)571-7.

\section{Correspondence:}

Renato Jahjah Cunha Martins

Rua Delfim Moreira, 6

11040-100 Santos - SP Brasil

Tel.: (55 13)3227-4224

renatojahjah@terra.com.br

Received: May 14, 2013

Review: July 15, 2013

Accepted: Aug 16, 2013

Conflict of interest: none

Financial source: none

${ }^{1}$ Research performed at Imaging Diagnosis Department, Federal University of Sao Paulo (UNIFESP), Brazil. Part of PhD degree thesis, Postgraduate Program in Radiology and Radiologic Sciences. Tutor: Prof. Henrique Manoel Lederman. 